GARCIA, Maria. Limites da ciência: a dignidade da pessoa humana: a ética da responsabilidade. São Paulo: Ed. Revista dos Tribunais, 2004.

GUERRA FILHO, Willis Santiago. Processo constitucional e direitos fundamentais. São Paulo: Instituto Brasileiro de Direito Constitucional; Celso Bastos, 1999.

KELSEN, Hans, 1881-1973. Teoria geral das normas. Tradução de José Florentino Duarte. Porto Alegre: Fabris, 1986.

MENDES, Gilmar Ferreira. Direitos fundamentais e controle de constitucionalidade: estudos de direito constitucional. São Paulo: Celso Bastos; Instituto de Direito Constitucional, 1998.

MIRANDA, Jorge. Manual de direito constitucional. 2. ed. rev. Coimbra: Coimbra Ed., 1988. t. 2.

NEVES, Marcelo. Teoria da Inconstitucionalidade das Leis. São Paulo: Saraiva, 1988.

RAMOS, Elival da Silva. A inconstitucionalidade das Leis: vício e sanção. São Paulo: Saraiva, 1994.

TAVARES, André Ramos: Curso de direito constitucional. 2. ed. rev. e ampl. São Paulo: Saraiva, 2003.

WIKIPEDIA, enciclopédia virtual. Disponível em <www.wikipedia.org>.

\title{
FundamentaÇão JuRídica da ResoluÇão N. 1.805/2006
}

\section{JURIDICAL BASIS FOR RESOLUTION N. 1.805/2006}

\author{
Livia Haygert Pithan (*) \\ Gustavo Silveira Borges ${ }^{(\star \star)}$
}

\section{INTRODUÇÃO}

O Conselho Federal de Medicina (CFM), no dia 28 de novembro de 2006, publicou uma polêmica resolução, aprovada por unanimidade, que permite aos médicos brasileiros suspender tratamentos e procedimentos

(*) Professora de Bioética e Direito da Pontifícia Universidade Católica do Rio Grande do Sul (PUCRS), mestre em Direito e doutoranda em Direito Privado na Universidade Federal do Rio Grande do Sul (UFRGS). E-mail: <liviahp@terra.com.br>.

("*) Advogado, especialista em Ciências Penais pela PUC-RS e mestrando em Ciências Criminais na PUC-RS. E-mail: <gustavoborges @ hotmail.com>. 
que prolonguem a vida de doentes terminais e sem chances de cura, desde que a família ou o paciente concorde com a decisão. ${ }^{(1)}$

No meio jurídico, porém, restam posicionamentos controvertidos sobre a licitude do procedimento médico de permitir a morte de pacientes para os quais a Medicina não tenha mais aptidão de beneficiar.

O presente texto tem como objetivo sustentar a adequação jurídica da referida resolução. Neste sentido, inicialmente apresentam-se argumentos oriundos da Associação Médica Mundial e da teologia moral da Igreja Católica, a fim de verificar em que medida os deveres morais de alcance internacional estão ou não contemplados pela nova diretriz do CFM.

Após considerações morais, passa-se a apresentar os fundamentos legais no Direito brasileiro que podem ser utilizados para defesa da ortotanásia, ou seja, para defesa da conduta médica que opta por não oferecer, suspender ou retirar recursos terapêuticos sabidamente ineficazes em pacientes no final de vida. Será que a inexistência de lei específica sobre o tema é suficiente para concluir pela ilicitude da resolução do CFM?

Finalmente, apresentam-se argumentos que afastam a relevância jurídico-penal da ortotanásia, ou seja, defende-se a inexistência de conduta médica criminosa ao permitir que pacientes morram com dignidade e sem excessos terapêuticos.

\section{I - POSICIONAMENTO MORAL DA ASSOCIAÇÃO MÉDICA MUNDIAL E DA IGREJA CATÓLICA}

A Resolução n. 1.805/2006 está de acordo tanto com a política apregoada pela Associação Médica Mundial (AMM) quanto com a teologia moral católica, como passamos a analisar.

Em 1983, através do documento chamado "Declaração de Veneza sobre Doença Terminal", a AMM expressamente permitiu a limitação terapêutica quando o paciente ou seus familiares o desejarem, afirmando que "o médico deve abster-se de utilizar medidas extraordinárias que não tragam benefícios para o paciente"(2). Neste sentido, a AMM ainda esclarece que "a não-implantação de um tratamento não libera o médico de sua obrigação de assistir à pessoa que está morrendo e fornecer-Ihe os medicamentos necessários para suavizar a fase terminal de sua doença".

(1) BRASIL. Conselho Federal de Medicina. Resolução n. 1.805/2006, publicada no Diário Oficial da União em 28 de novembro de 2006, Seção I, p. 169. Conforme a literalidade do texto, "Art. $1^{\circ} \dot{E}$ permitido ao médico limitar ou suspender procedimentos e tratamentos que prolonguem a vida do doente em fase terminal, de enfermidade grave e incurável, respeitada a vontade da pessoa ou de seu representante legal."

(2) ASSOCIAÇÃO MÉDICA MUNDIAL. Declaração de Veneza sobre Doença Terminal, 1983. In: GOLDIM, José Roberto. Disponivel em: <http://www.ufrgs.br/bioetica/veneza.htm>. 
A atitude médica de deixar de utilizar medidas excessivas e desnecessárias em pacientes que estão morrendo não se configura como "limitar ajuda a doente terminal", como interpretou, equivocadamente, título de reportagem do jornal Folha de São Paulo. A resolução não permite aos médicos matar os pacientes sem cura, mas possibilitar que eles morram dignamente, sem o uso de medidas heróicas sabidamente ineficazes.

É farta a literatura científica que distingue moralmente $o$ ato médico de "matar" pacientes e a omissão eticamente adequada que os "deixa morrer"(3), independentemente da morte ser a mesma conseqüência para ambas as situações.

O CFM não pretende, portanto, desonerar os médicos de assistir quem está morrendo ou de "limitar a ajuda" aos doentes, a menos que consideremos alguma espécie de "ajuda" o uso excessivo de recursos científicos e tecnológicos incapazes de reverter um estado terminal que contrarie a vontade do paciente e seus familiares.

A nosso ver, o CFM veio regulamentar nacionalmente uma diretriz ético-política internacional manifestamente contrária à obstinação terapêutica: atitude médica defensiva e onipotente de não aceitar a morte como desfecho natural da vida.

Em 1987, a mesma referida associação internacional publicou um documento denominado "Declaração sobre eutanásia", por ocasião da 39a Assembléia Mundial de Medicina, ocorrida em Madrid, na Espanha. Consta no documento a seguinte manifestação:

Eutanásia, que é o ato de deliberadamente terminar com a vida de um paciente, mesmo com a solicitação do próprio paciente ou de seus familiares próximos, é eticamente inadequada. Isso não impede o médico de respeitar o desejo do paciente em permitir o curso natural do processo de morte na fase terminal de uma doença. ${ }^{(4)}$

A AMM, portanto, considera moralmente distintas as situações de "matar" ou "deixar morrer" um paciente incurável. O respeito do médico à autonomia individual do paciente somado à assistência médica proporcional aos cuidados devidos consiste em garantir a dignidade do doente que está morrendo.

No mesmo sentido, pode-se encontrar o posicionamento da Igreja Católica que, contrariando as usuais acusações de conservadorismo, tem

(3) Por todos, veja-se os dois excelentes textos do Direito anglo-saxão: GOSTIN, Lawrence. Drawing a line between killing and letting die. The Journal of Law, Medicine \& Ethics, v. 21, n. 1 , p. 94-101, spring 1993. CULVER, K. C.; CUPPLES, Brian. Why witholding treatment is not assisted suicide. Health Law in Canada, v. 20, n. 2, p.12-16, nov.,1999.

(4) ASSOCIAÇÃO MÉDICA MUNDIAL. Declaração sobre eutanásia. In: GOLDIM, José Roberto. (Org.). Disponivel em: <http://www.ufrgs.br/HCPA/gppg/madrid.htm>, Acesso em: ago. 2001. Grifos nossos. 
tido a sensibilidade de se adaptar às sutilezas morais decorrentes do progresso da Medicina. Já em 1957, o Papa Pio XII admitiu a possibilidade da administração de narcóticos para aliviar a dor de doentes irrecuperáveis que, de maneira indireta e como efeito secundário, causam a morte: a chamada eutanásia de duplo efeito ou indireta ${ }^{(5)}$.

Mais recentemente, em um documento elaborado pela Sagrada Congregação para a Doutrina da Fé, em 1980, denominado "Declaração sobre a eutanásia", a Igreja Católica condena sua prática, mas a distingue de situações de rechaço à obstinação terapêutica. Este manifesto da Igreja define eutanásia como uma ação ou omissão que, por sua natureza e nas intenções, provoca a morte com o objetivo de eliminar o sofrimento(6).

Distinta da eutanásia é a decisão de renunciar ao chamado "excesso terapêutico", ou seja, a certas intervenções médicas já inadequadas à situação real do doente, porque não proporcionais aos resultados que se poderiam esperar ou ainda porque demasiado gravosas para ele e para sua familia. (...) A renúncia a meios extraordinários ou desproporcionados não equivale ao suicídio ou à eutanásia; exprime, antes, a aceitação da condição humana defronte a morte(7).

De acordo com o que foi exposto, observa-se que tanto as obrigações deontológicas dos médicos em nivel internacional, da $A M M$, e também a moral católica - de marcada influência na cultura ocidental - consideram eticamente adequado não oferecer ou suspender recursos terapêuticos avaliados como desnecessários ou excessivos. Interessante complementar que a Conferência Nacional dos Bispos do Brasil (CNBB) manifestou-se expressamente favorável à Resolução n. $1.805 / 2006$ do $C F M^{(8)}$.

\section{II - FUNDAMENTOS LEGAIS DA ORTOTANÁSIA NO DIREITO BRASILEIRO}

Em âmbito legislativo nacional, inexiste lei federal que trate especificamente dos direitos dos pacientes a recusar tratamento médico. Porém, encontra-se na produção teórica de juristas conectados à temática bioética a afirmação desse direito a partir da interpretação de vários dispositivos legais dispersos pelo ordenamento jurídico brasileiro, a começar pela própria Constituição Federal.

(5) GAFO FERNÁNDEZ, Javier. 10 palavras-chaves em bioética. Trad. Maria Luisa Garcia Prada. São Paulo: Paulinas, 2000.

(6) EVANGELIUM VITAE. Carta encíclica de João Paulo /l sobre o valor e a inviolabilidade da vida humana. 2 ed. São Paulo: Paulinas, 1995. p. 130.

(7) Id., loc. cit.

(8) CNBB divulga nota favorável à resolução da ortotanásia. Jornal O Globo, 11.11.2006. Disponivel em: <http://jornalnacional.globo.com/Jornalismo/JN/0,,AA1347256-3586,00.html>. 
A prática do consentimento informado ${ }^{(9)}$ na assistência médica tem respaldo jurídico não apenas no princípio constitucional da dignidade da pessoa humana, no inciso III do art. 1ำ mas também através da cláusula geral da liberdade, expressa no inciso 11 do art. $5^{\circ}$ da Constituição Federal de 1988, onde se afirma que "ninguém será obrigado a fazer ou deixar de fazer alguma coisa senão em virtude de lei"(10).

Essa norma constitucional afirma que se a lei não proíbe ou não impõe um dado comportamento, as pessoas têm autodeterminação para adotá-lo ou não. Portanto, "a liberdade consiste em ninguém ter de submeter-se a qualquer vontade senão a da lei, e, mesmo assim, desde que ela seja formal e materialmente constitucional"(11). Desse modo se pode afirmar que uma vez que a Constituição Federal garante que ninguém será obrigado a fazer ou deixar de fazer alguma coisa senão em virtude de lei, está-se diante da necessidade do consentimento informado e esclarecido do paciente para qualquer tipo de tratamento, não havendo disposição legal específica(12).

Além da referida cláusula geral da liberdade, no inciso 11 do art. 5 da Constituição Federal, também se encontram outros incisos do mesmo artigo que podem justificar o direito do doente recusar tratamento médico excessivo, como por exemplo:

III - ninguém será submetido a tortura nem a tratamento desumano ou degradante; IV - é livre a manifestação do pensamento (...); VI — é inviolável a liberdade de consciência e de crença (...); $X$ - são invioláveis a intimidade, a vida privada, a honra e a imagem das pessoas (...). $\S 2^{\circ}$ Os direitos e garantias expressos nesta Constituição não excluem outros decorrentes do regime e dos princípios por ela adotados, ou dos tratados internacionais em que a República Federativa do Brasil seja parte. ${ }^{(13)}$

O Código Civil, que entrou em vigor no início de 2003, apresenta um novo dispositivo legal que pode ser considerado, igualmente, como fundamentação do consentimento informado. $O$ art. 15 do Código Civil diz, literalmente, que "ninguém pode ser constrangido a submeter-se, com risco de vida, a tratamento médico ou à intervenção cirúrgica".

(9) Entende-se como consentimento informado a anuência do paciente ou dos sujeitos de pesquisa em se submeterem a procedimento diagnóstico, tratamento de saúde ou investigação, após ciência e esclarecimento adequado dos riscos e benefícios que possam surgir como conseqüência. (10) BRASIL. Constituição da República Federativa do Brasil. Promulgada em 5 de outubro de 1988. 25. ed. atual. e ampl. São Paulo: Saraiva, 2000.

(11) BARROSO, Luís Roberto. Eficácia e efetividade do direito à liberdade. In: ANAIS DA XVII CONFERÊNCIA NACIONAL DOS ADVOGADOS: Justiça: realidade e utopia. Brasilia: OAB, Conselho Federal, 2000. p. 757-769.

(12) BORGES, Roxana Cardoso Brasileiro. Direito de morrer dignamente. In: SANTOS, Maria Celeste Cordeiro Leite (Org.). Biodireito. São Paulo: Ed. Revista dos Tribunais, 2001. p. 283-305. (13) BRASIL. Constituição da República Federativa do Brasil. Promulgada em 5 de outubro de 1988. 25. ed. atual. e ampl. São Paulo: Saraiva, 2000. 
Além do âmbito federal, tem-se a Lei Estadual Paulista n. 10.245/99 que trata dos direitos dos usuários do sistema de saúde no estado de São Paulo e possibilita aos doentes recusar tratamento médico no art. $2^{\circ}$, inciso XXIII, ao afirmar que é direito do paciente "recusar tratamentos dolorosos ou extraordinários para tentar prolongar a vida"(14).

Curiosamente, um ano após a promulgação da referida lei sobre os direitos dos usuários dos serviços de saúde de São Paulo, o então governador Mário Covas recusou tratamento médico em final de vida. Sofrendo de câncer terminal, Covas decidiu não se submeter a tratamento médico em unidade de terapia intensiva de hospital, preferindo morrer em casa(15).

Outro documento normativo que auxilia na interpretação da dignidade da pessoa humana no momento da morte é a Resolução n. 41/95 do Conselho Nacional dos Direitos da Criança e do Adolescente (CONANDA), órgão vinculado ao Ministério da Justiça. Esta resolução aprovou na íntegra um texto elaborado pela Sociedade Brasileira de Pediatria, relativo aos direitos da criança e do adolescente hospitalizados.

Enquanto a Lei n. 8.069/90 - o Estatuto da Criança e do Adolescente - diz em seu art. 15 que a criança e o adolescente têm direito à dignidade, a Resolução(16) n. 41/95 do CONANDA assegura ao paciente jovem ou infante, no art. 20, o "direito a ter uma morte digna, junto a seus familiares, quando esgotados todos os recursos terapêuticos disponíveis"(17).

Significa dizer que quando os recursos terapêuticos disponiveis tiverem esgotado as possibilidades de beneficiar a criança ou o jovem hospitalizado, ou seja, quando o processo de morte for irreversível, o direito à morte digna equivale a não intervir medicamente de forma abusiva ou desnecessária. Assim, a criança ou jovem que estejam morrendo têm o direito de morrer em casa, sem serem submetidos à obstinação terapêutica.

Os diversos dispositivos legais esparsos descritos anteriormente, somados à presunção de legalidade da resolução do CONANDA e da constitucionalidade da lei paulista referente aos usuários dos serviços de saúde

(14) ESTADO DE SÃO PAULO. Lei n. 10.241, publicada no Diário Oficial do Estado de São Paulo em 17 de março de 1999.

(15) Conforme William Saad Hossne, esta mesma decisão do governador Mário Covas há cerca de 20 anos atrás traria enormes dificuldades. Vide: HOSSNE, William Saad. Entre a ética, a fé e a ciência. (Entrevista) Época, São Paulo, 27 ago. 2001. 27 de agosto de 2001, p. 54-56.

(16) Impõe esclarecer o sentido jurídico de uma resolução, que é uma forma de exteriorização de um ato administrativo. Ato administrativo, por sua vez, é toda prescrição, juízo ou conhecimento predisposto à produção de efeitos jurídicos, expedida pelo Estado ou por quem Ihe faça as vezes, no exercicio de suas prerrogativas estabelecida na conformidade da lei, sob o fundamento de cumprir finalidades assinaladas no sistema normativo. GASPARINI, Diógenes. Direito administrativo. 4. ed. São Paulo: Saraiva, 1995, p. 62.

(17) BRASIL. Ministério da Justiça. CONANDA - Conselho Nacional dos Direitos da Criança e do Adolescente. Direitos da criança e do adolescente hospitalizados. Resolução n. 41/95, publicada no Diário Oficial da União, Seção 1, de 17 de outubro de 1995. 
do estado de São Paulo fazem crer que o direito a recusar tratamento médico ineficaz existe independentemente de haver lei federal específica sobre o tema.

\section{III - A ORTOTANÁSIA NÃO CONSISTE EM UMA OMISSÃO PENALMENTE RELEVANTE}

A questão envolvendo a ortotanásia tem sido abordada pelos juristas, sob o ponto de vista jurídico-penal, de forma simplificada, tendo em vista que as práticas consideradas como eutanásicas são igualadas jurídico-penalmente mediante a singela e restrita interpretação gramatical da legislação vigente. De um modo geral, com elasticidade que se dão as variáveis acepções do termo, a questão é tratada como crime de homicídio privilegiado ou mesmo homicídio por omissão no Direito Brasileiro.

Não podemos olvidar o momento histórico inspirador desta tomada de posição rígida, simplista e generalista, dentre estes, alguns doutrinadores imbuídos pelo espírito do vetusto Código Penal de 1940, abordaram a questão no item 39 da Exposição de Motivos do Código Penal(18) (Decreto-Lei n. 2.848/40), talvez por isso, não se tenha dado a devida e merecida acuidade ao tema. Essas posições expressam o tratamento jurídico-penal até então outorgado à eutanásia que necessita, urgentemente, ser rediscutida em termos legislativos.

Há divergência em doutrina acerca da questão da ortotanásia. Maria Celeste Cordeiro Leite Santos, por exemplo, entende que na omissão médica no sentido de não intervir no espaçamento da vida do paciente além do seu período natural, salvo se for por ele expressamente requerido, tratarse-ia de uma causa de exclusão de ilicitude com amparo no exercício regular de um direito (art. 23 do Código Penal)(19).

Tentou-se, através de algumas leis, definir o momento da morte, por exemplo, com advento da Lei n. 9.434/97(20), que definiu a morte encefálica como sendo o momento da morte para fins de transplante. Contudo, pouco se avançou em termos de dogmática, sobretudo, no tratamento jurídicopenal arraigado e parado no tempo em descompasso com outras áreas do conhecimento, como a bioética, que possibilita essa interface epistemológica.

Esse novo paradigma incitou discussões sobre a limitação dos recursos técnicos excessivos tendentes a prolongar a vida de doentes em fase

(18) Cf. Exposição de Motivos da Parte Especial do Código Penal: p. 266: Por "motivo de relevante valor social ou moral", o projeto entende significar o motivo que, em si mesmo, é aprovado pela moral prática, como, por exemplo, a compaixão ante o irremediável sofrimento da vítima (caso o homicídio eutanásico), a indignação contra um traidor da pátria, etc.

(19) SANTOS, Maria Celeste Cordeiro Leite dos. Contornos atuais da eutanásia e da ortotanásia: Bioética e Biodireito. A necessidade do controle social das técnicas médicas. Revista da Faculdade de Direito da USP, São Paulo, p. 265-278, 1999.

(20) Dispõe sobre a remoção de órgãos, tecidos e partes do corpo humano para fins de transplante e tratamento e dá outras providências. 
terminal, acometidos de enfermidade grave e incurável, defendidos pela Resolução do Conselho Federal de Medicina n. 1.805/06, já em vigor no país, que amplia sobremaneira a adequação dos limites éticos da questão. Escassos os textos jurídico-criminais que versam sobre a matéria, de modo que se faz necessário um esforço investigativo na obtenção de uma visão da ortotanásia, congregando à dogmática uma visão ética.

Pela simples leitura do art. $13, \S 2^{\circ}$, alínea $b$, do Código Penal, parece claro que no momento em que decide não postergar a vida de pacientes em fase terminal de enfermidades graves e incuráveis, ainda que mantidos unicamente de forma artificial, mesmo que se saiba, de antemão, de acordo com a tecnologia contemporânea, que a empreitada esteja fadada ao insucesso, ainda que cause muita dor e sofrimento ao paciente, o médico será guindado, pela legislação, à posição de garantidor. E, como tal, incorreria imediatamente na adequação típica do delito de homicídio omissivo impróprio, já que pela legislação, podia e devia agir para evitar o resultado.

Todavia, é possivel perquirir acerca de uma atipicidade da ortotanásia, a partir de um estudo do jurista argentino Zaffaroni(21), que bem diferencia dentro da tipicidade, o tipo legal do tipo penal, aludindo que este último abrangeria o tipo legal acrescido do que denomina de antinormatividade. Propõe o autor estabelecer uma limitação jurídico-penal nos casos de ortotanásia, porquanto, já se pode, mediante a tipicidade conglobante, somada aos argumentos da bioética, da deontologia médica e dos princípios constitucionais, classificá-la como conduta atípica - pela falta de tipicidade penal - já que a conduta de abster-se de realizar procedimento para manter artificialmente a vida de um paciente em estado terminal irreversivel não violaria a norma que deu origem ao tipo legal, pois não the seria dispensado tratamento necessário, já que se sabe da pouca duração futura de sua vida. Para Zaffaroni, a norma - que dá ensejo ao tipo legal - não pode estar em conflito com outras normas do sistema, sob pena de se arranhar toda a ordem normativa.

Assim, o médico, diante de tais situações não se coloca na posição de garantidor, de modo que não se enquadra na omissão penalmente relevante do art. $13, \S 2^{\circ}$, do Código Penal.

No debate legislativo jurídico-penal, é possivel encontrar algumas referências sobre a ortotanásia ${ }^{(22)}$ ao longo da história, mais atualmente, podemos referir que no Brasil, em 1996, foi proposto no senado um Projeto de Lei $n$. 125/96, com o intuito de instituir a possibilidade de realização de procedimentos de ortotanásia; no entanto, a avaliação do projeto nas comissões especializadas não se desenvolveu. Já o anteprojeto da parte especial

(21) ZAFFARONI, Eugenio Raúl; PIERANGELI, José Henrique. Manual de direito penal brasileiro: parte geral. 5. ed. São Paulo: Ed. Revista dos Tribunais, 2004. p. 522-536.

(22) GOLDIM, José Roberto. Núcleo interdisciplinar de bioética. Disponivel em: $<w w w$. bioética.ufrgs.br.htm>. 
do Código Penal de 1984, que está em tramitação no Senado Federal, traz um avanço expressivo no tratamento dado ao polêmico tema da ortotanásia, ao afirmar expressamente no art. 121, $\S 3^{\circ}$ : "Não constitui crime deixar de manter a vida de alguém por meio artificial se previamente atestada por dois médicos, a morte como iminente inevitável, e desde que haja consentimento do doente ou, na sua impossibilidade, de ascendente, descendente, conjugue ou irmão". A aprovação desse projeto permitirá que a ortotanásia seja legalmente realizada, evitando, assim, o prolongamento indevido da vida de um paciente terminal, encurtando o seu sofrimento, de modo a se permitir um final de vida digno e condizente com os preceitos constitucionais.

Assim, um direito penal melhor é aquele que reduz seu poder punitivo(23), abrindo espaço para modelos eficazes de solução de conflitos que serão sempre condições melhores que o poder punitivo desenfreado(24). Portanto, diante da realidade dos procedimentos eutanásicos já realizados dentro dos hospitais diuturnamente, importante reavaliar a limitação ao poder punitivo, já que a ortotanásia não consiste numa omissão penalmente relevante.

\section{CONSIDERAÇÕES FINAIS}

Conforme mencionado previamente, procurou-se, com o presente artigo, sustentar juridicamente a Resolução n. 1.805/06, que permite à classe médica se omitir de uma prática abusiva no uso da ciência e tecnologia.

O Conselho Federal de Medicina mostrou coragem e adequação ética ao aprovar e publicar tal resolução. Está de acordo com a Associação Médica Mundial, que considera inadequada a obstinação terapêutica, prolongando com sofrimento o processo de morte. No mesmo sentido, também está de acordo com a posição moral da Igreja Católica, que considera eticamente correta a posição médica de se limitar ao uso de recursos terapêuticos proporcionais ao estado de doença do paciente.

O Direito brasileiro, por outro lado, não possui legislação específica que regulamente a prática da limitação terapêutica em final de vida. Porém, isto não significa que nosso ordenamento jurídico não tenha dispositivos legais aptos a serem interpretados de forma eticamente adequada.

(23) Cf. ZAFFARONI, E. Raúl, BATISTA, Nilo, Direito penal brasileiro, p. 156-157: frisam que o Direito Penal deve programar o exercício do poder jurídico como um dique que contenha o estado de polícia, impedindo que afogue o estado de direito. Entretanto, as águas do estado de polícia se encontram sempre em um nivel superior, de modo que ele tende a ultrapassar o dique por transbordamento. Para evitar isso, deve o dique dar passagem a uma quantidade controlada de poder punitivo, fazendo-o de modo seletivo, filtrando apenas a torrente menos irracional e reduzindo sua turbulência, mediante um complicado sistema de comportas que impeça a ruptura de qualquer uma delas e que, caso isto ocorra, disponha de outras que reassegurem a contenção.

(24) ZAFFARONI. op. cit., p. 153. 
Percebe-se que, a partir da Constituição Federal, do Código Civil, da Lei Paulista dos Usuários dos Serviços de Saúde, bem como da Resolução do CONANDA, que a nova Resolução do CFM, que permite a ortotanásia, está, sim, de acordo com a legislação brasileira e merece ampla discussão para sua correta aplicação.

Verifica-se, sem dúvidas, que muito ainda precisa ser estudado e pesquisado, até que se encontrem conclusões definitivas que auxiliem, de forma consistente, a dar respostas efetivas para os questionamentos feitos diariamente no ambiente hospitalar. Espera-se, do Direito brasileiro, que o medo e a covardia não imobilizem o desenvolvimento do conhecimento jurídico, de forma a nos tornar reféns da intervenção pontual legislativa.

Percebe-se, portanto, a necessidade de um debate transdisciplinar para o alcance de soluções eticamente corretas, já que a ciência jurídica, por si só, não está apta a dar soluções satisfatórias para conflitos da mais alta complexidade como os bioéticos.

\section{REFERÊNCIAS}

ASSOCIAÇÃO MÉDICA MUNDIAL. Declaração de Veneza sobre Doença Terminal. In: GOLDIM, José Roberto. Disponivel em: <http://www.ufrgs.br/ bioetica/veneza.htm>, 7.1.2007.

ASSOCIAÇÃO MÉDICA MUNDIAL. Declaração sobre eutanásia. In: GODIM, José Roberto (Org.). Disponível em: <http://www.ufrgs.br/bioetica/ madrid.htm>, 7.1.2007.

BORGES, Gustavo Silveira. Uma breve reflexão interdisciplinar acerca da eutanásia passiva. Revista de Estudos Criminais, São Paulo, p. 159-177, 2006.

BRASIL. Ministério da Justiça. CONANDA - Conselho Nacional dos Direitos da Criança e do Adolescente. Direitos da criança e do adolescente hospitalizados. Resolução n. 41/95, Diário Oficial da União, Seção 1, de 17 de outubro de 1995.

. Código Penal. Exposição de Motivos da Parte Especial. Luiz Flávio Gomes (Org.). Diário do Congresso, 31 de dezembro de 1940. 5. ed. São Paulo: Saraiva, 2003.

Conselho Federal de Medicina - CFM. Resolução n. 1.805/2006. Diário Oficial da União, Seção 1, de 28 de novembro de 2006.

CNBB divulga nota favorável à resolução da ortotanásia. O Globo, 11.11.2006. Disponivel em: <http://jornalnacional.globo.com/Jornalismo/JN/0, AA1347256-3586,00.html>.

COLLUCCI, Cláudia. Médico pode limitar ajuda a doente terminal. Folha de S. Paulo. 10.11.2006. Disponivel em: <http://www1.folha.uol.com.br/folha/cotidiano/ult95u128054.shtml>. 
CULVER, K. C.; CUPPLES, Brian. Why witholding treatment is not assisted suicide. Health Law in Canada, v. 20, n. 2, p.12-16, nov.,1999.

ESTADO DE SÃO PAULO. Lei n. 10.241. Diário Oficial do Estado de São Paulo em 17 de março de 1999.

EVANGELIUM VITAE. Carta encíclica de João Paulo // sobre o valor e a inviolabilidade da vida humana. 2. ed. São Paulo: Paulinas, 1995.

FRAGA, Márcio André Keppler. A atipicidade penal da ortotanásia. Revista da Ajuris, v. 26, n. 78, p. 163-168, jun. 2000.

GAFO FERNÁNDEZ, Javier. 10 palavras-chaves em bioética. Trad. Maria Luisa Garcia Prada. São Paulo: Paulinas, 2000.

GASPARINI, Diógenes. Direito administrativo. 4. ed. São Paulo: Saraiva, 1995.

GOSTIN, Lawrence. Drawing a line between killing and letting die. The Journal of Law, Medicine \& Ethics, v. 21, n. 1, p. 94-101, spring 1993.

HOSSNE, William Saad. Entre a ética, a fé e a ciência. (Entrevista) Época, São Paulo: 27 ago. 2001, p. 54-56.

PITHAN, Lívia Haygert. A dignidade humana como fundamento jurídico das "ordens de não-ressuscitação". Porto Alegre: EDIPUCRS, 2004.

SANTOS, Maria Celeste Cordeiro Leite dos. Contornos atuais da eutanásia e da ortotanásia: bioética e biodireito. A necessidade do controle social das técnicas médicas. Rev. da Fac. Direito USP, São Paulo, p. 265-278, 1999.

ZAFFARONI, Eugênio Raúl; BATISTA, Nilo. Direito penal brasileiro. Rio de Janeiro: Revan, 2003.

ZAFFARONI, Eugenio Raúl; PIERANGELI, José Henrique. Manual de direito penal brasileiro: Parte Geral. 5. ed. São Paulo: Ed. Revista dos Tribunais, 2004.

\section{Morte Digna: Direito Natural do Ser Humano}

DIGNITY IN DEATH: NATURAL RIGHT OF HUMAN BEING

Fernando Aith ${ }^{(\star)}$

Em 28 de novembro de 2006 o Conselho Federal de Medicina (CFM) tomou uma decisão polêmica que representa um importante marco regula-

(*) Doutor em Saúde Pública pela Faculdade de Saúde Pública da Univerisdade de São Paulo (FSP. USP), especialista em Direito Médico e da Saúde pela Universidade de Paris 8, mestre em Filosofia e Teoria Geral do Direito pela Faculdade de Direito da USP, pesquisador do Centro de Estudos e Pesquisas de Direito Sanitário e professor de Redação e Estratégia Legislativa da Escola de Direito da Fundação Getúlio Vargas - EDESP-FGV/SP. E-mail: <feaith@uol.com.br>. 